\title{
ESTOQUE DE CARBONO EM ÁREAS AGRÍCOLAS EM FUNÇÃO DO USO E MANEJO DO SOLO
}

Gisele Santos Raminelli, Barbara Pereira Gomes, Isabela Marega Rigolin, Carlos Henrique dos Santos

Universidade do Oeste Paulista - UNOESTE.

\section{RESUMO}

As coletas foram realizadas em áreas do campus II da Unoeste, Presidente Prudente/SP, em área de cana-de-açúcar seu cultivo está no segundo corte, ambos sem queima, o eucalipto possui 8 anos, este foi plantado com um manejo inadequado do solo para o cultivo do mesmo, e a mata nativa possui aproximadamente seis anos, e não possui intervenção antrópica. $O$ delineamento experimental utilizado foi caracterizado como inteiramente casualizado (DIC), estruturado em parcelas subdivididas, onde as parcelas foram denominadas de sistemas de manejo e as subparcelas as profundidades de solo amostradas. As amostragens foram realizadas no mês de outubro de 2012, as profundidades foram de 0-5, 5-10, 10-20 e 20-40 cm. Após a coleta, as amostras foram transportadas para o laboratório de análise de solos da UNOESTE para a determinação dos parâmetros químicos do solo (análise básica), teor de carbono e densidade do solo. Os resultados obtidos foram submetidos à análise de variância (Teste $F$ ), avaliando-se o efeito dos tratamentos pelo teste de Tukey ao nível de 5\% de probabilidade. Neste trabalho podese concluir que: a ocupação do solo com cana-de-açúcar ou eucalipto podem ser alternativas viáveis para melhorar o sequestro de $\mathrm{CO} 2$ atmosférico, quando estas forem manejadas de forma adequada, a cana-de-açúcar obteve o maior estoque de carbono no solo; a mata nativa está em recuperação do solo e tende a aumentar os estoques de carbono com o passar dos anos, pois esta ainda é recente e os manejos adequados de solos agrícolas podem melhorar a retirada de carbono da atmosfera.

Palavras chave: Seqüestro de Carbono, Qualidade do Solo, Matéria Orgânica, Meio Ambiente

\section{INTRODUÇÃO E JUSTIFICATIVA}

As atividades realizadas no cotidiano, de forma indireta ou direta colaboram para a emissão de gases de efeito estufa (GEE), como por exemplo, através dos produtos que consumimos. Quando essas concentrações são alteradas em quantidades muito acima dos parâmetros considerados normais no ambiente, podem causar um aumento da temperatura do planeta, como mostra os dados do IPCC, que revelam que a temperatura média global pode aumentar entre 1,4 a $5,8^{\circ} \mathrm{C}$ nos próximos 100 anos.

Esse gás de efeito estufa, sendo o gás carbônico o que mais contribui para o aquecimento global, permanece na atmosfera por um longo tempo, este tema já vem sendo motivo de discussão e preocupação, principalmente após a criação do documento conhecido como Protocolo de Quioto ser assinado, onde neste documento os países se comprometem a reduzir as taxas de emissão de gases de efeito estufa. 
Uma das medidas encontradas para reduzir as taxas de emissões de carbono, foi à pesquisa para substituir os combustíveis fósseis, petróleo e carvão, por combustíveis ecologicamente corretos, ou seja, os biocombustíveis. E o Brasil possui um clima favorável para o cultivo da cana-de-açúcar, e a tecnologia para a produção do etanol possui a mesma como matéria prima.

O Brasil é o maior produtor mundial de cana-de-açúcar $(33,9 \%)$, e segundo Carvalho (2006) - Estimativas recentes indicam que os mercados potenciais (interno e externo) para o etanol e açúcar brasileiro usariam em 2012-2013 cerca de 685 milhões de toneladas de cana, produzidas em 6,4 milhões de hectare. Visando esta grande demanda ao uso da cana-de-açúcar este trabalho visa quantificar o estoque de carbono em cultivo com a mesma, realizar uma analise comparativa com as culturas de eucalipto e mata nativa e verificar se esta estoca uma quantidade de carbono de modo a colaborar com o seqüestro de $\mathrm{CO} 2$ da atmosfera.

As amostras foram coletadas em área experimental do campus II, da Universidade do Oeste Paulista, em Presidente Prudente/ SP, na região do Oeste Paulista.

A Figura 1 representa os pontos onde foram realizadas as coletas de amostragem para a realização de análises.

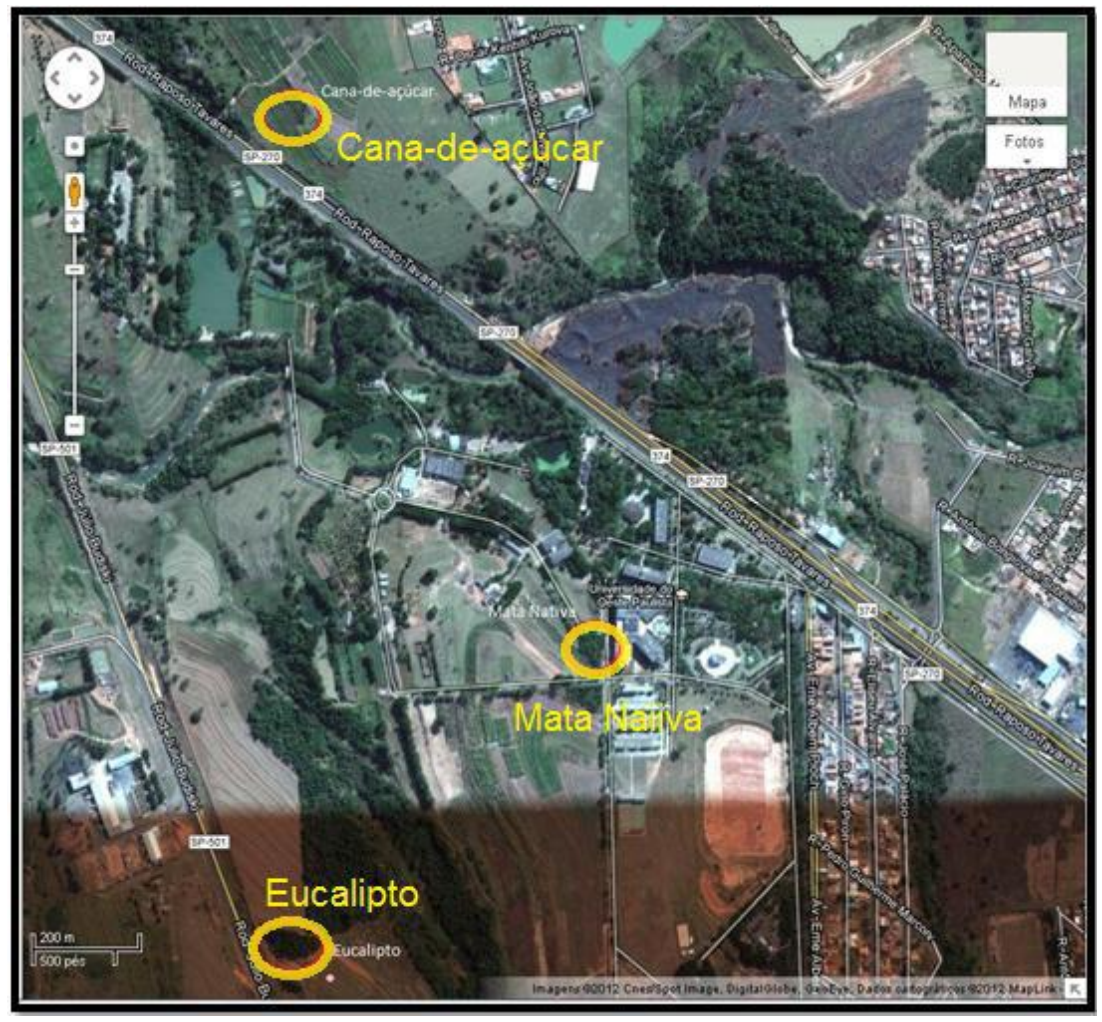

Figura 1. Área de localização.

Fonte - Google Earth, 2012. 
Antes de iniciar com as avaliações foi realizado um levantamento completo dos manejos utilizados nas áreas escolhidas e a caracterização das mesmas, para que possam fornecer subsídios durante a fase de discussão de resultados.

\section{OBJETIVO}

Quantificar e avaliar os estoques de carbono no solo, em áreas de cana de açúcar, eucalipto e mata nativa, comparando assim os resultados obtidos da quantidade de carbono estocado, e avaliando as quantidades retiradas de $\mathrm{CO} 2$ da atmosfera.

\section{METODOLOGIA}

Os sistemas serão selecionados de acordo com o histórico de uso:

(1) MN - Área de Mata Nativa;

(2) EC - Área de cultivo de Eucalipto;

(3) CA - Área de cultivo de Cana-de-açúcar.

A MN representa uma área que está em processo de reconstrução, pois foi degradada, sofrendo erosão, e a 6 (seis) anos reflorestaram para que o solo se reconstituísse. A EC representa uma área onde foi realizado um manejo de forma inadequada, num período de aproximadamente 8 (oito) anos. A CA representa uma área onde já foram realizadas duas colheitas da cana-deaçúcar, sem queima no canavial, colheita manual, presença de palhada seca resultante do corte e que já houve vários tipos de manejo, assim como outras culturas, como o milho, nesta área nas culturas anteriores a cana-de-açúcar também obteve adubação.

O delineamento experimental utilizado foi caracterizado como inteiramente casualizado (DIC), estruturado em parcelas subdivididas, onde as parcelas foram denominadas de sistemas de manejo e as subparcelas as profundidades ( 0-5, 5-10, 10-20 e 20-40 cm) de solo amostradas.

As amostragens foram coletadas, em profundidades de 0-5, 5-10, 10-20 e 20-40 cm, na entrelinhas da cultura. Após a coleta, as amostras foram encaminhadas para o laboratório de análise de solos da UNOESTE para a determinação dos parâmetros químicos do solo Matéria Orgânica (g dm-3), Carbono (g dm-3) de acordo com metodologia de RAlJ et al. (2001). O teor de Carbono Orgânico total (C) foi determinado pelo método de Walkley-Black (1934) citado em Raij et al. (2001). 
Os valores de densidade do solo (Ds) nas camadas referenciadas acima foram determinados em amostras indeformadas de solo (duas em cada parcela) coletadas, utilizando um anel cilíndrico de aço inox com volume de 0,098 dm3.

Para a realização das análises de matéria orgânica e carbono total foram coletadas amostras deformadas, uma por profundidade em cada trincheira, sempre sendo coletadas após a segunda amostra indeformada, estas foram armazenadas em caixinhas de papelão.

Após este processo, o solo foi seco em estufa de ar circulado em temperatura de $100{ }^{\circ} \mathrm{C}$ por 4 dias, para a retirada da umidade das amostras de solos nos anéis, 0 cálculo da densidade do solo foi realizado da seguinte forma: Ds = massa de solo seco/volume do cilindro.

Os estoques de carbono no solo em cada área foram calculados com base em massa equivalente de solo (Elbert \& Bettany, 1995) de acordo com a seguinte formula: \{Teor de $\boldsymbol{C}$ x $\boldsymbol{E}$ x $D$ \}, em que $\mathbf{C}=$ valor em g $\mathrm{kg}-1, \mathrm{E}=$ espessura da camada $(\mathrm{dm})$ e $\mathrm{D}=$ densidade do solo $(\mathrm{kg} \mathrm{dm}-3)$ na camada.

Os resultados obtidos foram submetidos à análise de variância (Teste F), avaliando-se o efeito dos tratamentos pelo teste de Tukey ao nível de $5 \%$ de probabilidade.

\section{RESULTADOS}

Na Tabela 1, analisando os dados obtidos pelo teste $F$, pode-se observar que não houve diferença significativa para o parâmetro densidade do solo com relação à profundidade e aos sistemas de manejo nas três áreas analisadas, sendo elas MN, CA e EC.

Tabela 1. Valores de F calculados pela análise de variância para o parâmetro de Densidade do Solo $\left(\mathrm{kg} / \mathrm{dm}^{3}\right)$.

MANEJOS

\begin{tabular}{lccc}
\hline Profundidade & & & \\
\hline & EC & MN & CA \\
\hline $0-5$ & 2,10 & 2,21 & 2,14 \\
$5-10$ & 2,23 & 2,15 & 2,23 \\
$10-20$ & 2,22 & 2,31 & 2,30 \\
$20-40$ & 2,26 & 2,28 & 2,23 \\
\hline
\end{tabular}

Não foi aplicado o teste de comparação de médias por que o F de interação não foi significativo.

$\mathrm{Na}$ Tabela 2, pode-se observar que houve diferença significativa no teor de matéria orgânica (MO) com relação às áreas de manejo analisadas, obteve-se um resultado não significativo para as dadas profundidades. 
Tabela 2. Valores obtidos a partir da análise estatística para a Matéria Orgânica do solo nos diferentes tipos de manejo.

\begin{tabular}{lcc} 
& \multicolumn{2}{c}{ MANEJOS } \\
\hline $\mathrm{EC}$ & $7,57 \mathrm{a}$ & \\
$\mathrm{MN}$ & $5,75 \mathrm{c}$ & \\
$\mathrm{CA}$ & $6,62 \mathrm{~b}$ & \\
\hline $\mathrm{dms}=$ & & 0,79 \\
\hline
\end{tabular}

$\mathrm{Na}$ Tabela 3, observa-se a interação entre os tipos de manejo e as profundidades no parâmetro estoque de carbono, expresso em t por hectare.

Tabela 3. Médias de interação: Manejo e Profundidade

\begin{tabular}{|c|c|c|c|c|}
\hline \multicolumn{5}{|c|}{ Profundidade $(\mathrm{cm})$} \\
\hline Manejo & & & & \\
\hline & $0-5$ & $5-10$ & $10-20$ & $20-40$ \\
\hline EC & $67,03 \mathrm{aB}$ & $44,10 \mathrm{aC}$ & $78,60 \mathrm{aB}$ & $163,05 \mathrm{aA}$ \\
\hline$M N$ & $37,83 \mathrm{bc}$ & $41,44 \mathrm{aC}$ & $74,30 \mathrm{aB}$ & $128,58 \mathrm{bA}$ \\
\hline CA & $43,54 \mathrm{bc}$ & $44,13 \mathrm{aC}$ & $90,73 \mathrm{Ab}$ & $164,70 \mathrm{aA}$ \\
\hline
\end{tabular}

$\mathrm{dms}$ para colunas $=17,6559 \mathrm{dms}$ para linhas $=19,3168$.

Classificação.c/letras minúsculas Classificação.c/letras maiúsculas. As médias seguidas pela mesma letra não diferem estatisticamente entre si.

\section{DISCUSSÃO}

Analisando os dados obtidos pelo teste $F$, pode-se observar que não houve diferença significativa para o parâmetro densidade do solo com relação à profundidade e aos sistemas de manejo nas três áreas analisadas, sendo elas MN, CA e EC. Os dados da Ds se mostraram com valores elevados, que indica que o solo possui características de solo sem manejo físico adequado. Segundo Camargo \& Alleoni (1997), solos com Ds adequados estão compreendidos na faixa de 1,0 e $1,2 \mathrm{~g} \mathrm{~cm}^{-3}$.

Esses maiores valores para a densidade podem resultar numa maior degradação física do solo nas áreas em estudo, o que indicam uma possível compactação e/ou adensamento do solo.

Houve diferença significativa no teor de matéria orgânica (MO) apenas com relação às áreas de manejo analisadas, obteve-se um resultado não significativo para as dadas profundidades, com relação aos diferentes cultivos, o manejo que apresentou um maior valor de 
matéria orgânica foi o eucalipto, por ser uma área sem intervenção humana, estar coberta por vegetação rasteira e folhas secas.

A MN obteve a menor quantidade de MO, esta possui 6 anos sem interferência, mas este ainda não foi suficiente para a sua reconstituição. Já no solo com a CA, os valores de $M O$ obtidos foram satisfatórios, devido à presença de palhada no solo e, esta área antes da CA, já havia recebido outro cultivo, de milho.

Observa-se a interação entre os tipos de manejo e as profundidades no parâmetro estoque de carbono, expresso em t por hectarie. Com relação aos manejos de EC, MN e CA os maiores estoques de carbono foram encontrados nas profundidades de $10-20$ e $20-40 \mathrm{~cm}$ em todos os manejos analisados, porém, o que apresentou um melhor estoque foi a CA em números, pois a EC não teve diferença significativa em relação a CA, pois os valores obtidos entre ambas foram muito próximos, sendo considerada esta diferença, não sigficativa pelo teste $F$. Consequentemente, as menores quantidades foram encontradas mais próximas à superfície, 0-5 e 5-10 cm, pois a matéria orgânica é mais facilmente degrada por conta de uma maior quantidade de microrganismos.

Quanto às profundidades de 0-5, 5-10, 10-20 e 20-40 cm, observa-se que na superfície, 0$5 \mathrm{~cm}$, a área que ocorreu uma maior estocagem do carbono foi a EC, por estar a vários anos sem interferência humana, possuir vegetação rasteira e liberar massa. Nas profundidades de 5-10 e 10$20 \mathrm{~cm}$, não houve diferença significativa quanto à estocagem de carbono. Já na profundidade de 20-40 cm, obteve os maiores quantidades de carbono estocada em todas as áreas, por conta da quantidade de raízes encontradas e também por já ser um solo mais profundo, que já possuiu estocagens anteriores, a MN obteve a quantidade de carbono estocado no solo inferior as áreas de EC e CA, porém esta está em reconstituição de sua área, pois anterior ao plantio desta mata, a área era muito degradada e erodida.

\section{CONCLUSÃO}

Com base nos resultados apresentados podemos concluir que:

- O solo cultivado com eucalipto proporciona condições satisfatórias para o estoque de carbono, por não haver intervenções em sua área, possuir um solo coberto com vegetação rasteira e folhas, o que isso possibilitou o acúmulo de matéria orgânica e a proteção contra agentes intempéricos. 
- A mata nativa mesmo sendo reconstituída recentemente (6 anos), possui características de recuperação e com o passar dos anos o estoque de carbono tende a aumentar. As quantidades de carbono estocadas aumentam com a profundidade devido a presença de raízes e ao estoque de carbono acumulado há muito tempo;

- A ocupação do solo com Cana-de-açúcar (CA) ou Eucalipto (EC) pode ser uma alternativa viável para melhorar o sequestro de $\mathrm{CO} 2$ atmosférico, quando estas forem manejadas de forma adequada. Neste experimento a CA obteve o maior estoque de carbono no solo;

- Manejos adequados de solos agrícolas podem melhorar a retirada de carbono da atmosfera, via fotossíntese das plantas, atenuando os efeitos do $\mathrm{CO} 2$ como integrante dos gases que contribuem para o efeito estufa;

\section{REFERÊNCIAS}

CARVALHO, E. P. Formulação de uma estratégia para garantir o aumento da produção. In: Seminário "Uma estratégia para o etanol brasileiro". Rio de Janeiro: Casa do Brasil, nov. 2006.

CAMARGO, O. A. de; ALLEONI, L. R. F. Compactação do solo e o desenvolvimento das plantas. Piracicaba: USP/ESALQ, 1997.

ELLERT, B.H. \& BETTANY, J.R. Calculation of organic matter and nutrients stored in soils under contrasting management regimes. Canadian J. Soil Sci., 75:529-538, 1995. http://dx.doi.org/10.4141/cjss95-075

IPCC: Disponível em: http://www.ipcc.ch/ Acesso em 7 de setembro de 2012

RAIJ, B.van; ANDRADE, J.C.; CANTARELLA, H. \& QUAGGIO, J.A. Determinação da Matéria Orgânica. In: RAIJ, B.van; ANDRADE, J.C.; CANTARELLA, H. \& QUAGGIO, J.A., eds. Análise química para avaliação da fertilidade de solos tropicais. Campinas, Instituto Agronômico de Campinas, 2001. p.189-199.

WALKLEY, A. \& BLACK, I.A. An examination of the Degtjareff method for determining soil organic matter and a proposed modification of the chromic acid titration method. Soil Sci., 37:29-38, 1934. http://dx.doi.org/10.1097/00010694-193401000-00003 